\title{
Inhibition of Ovarian Tumor Growth by Targeting the HU177 Cryptic Collagen Epitope
}

\author{
Jennifer M. Caron, ${ }^{*}$ Jacquelyn J. Ames, ${ }^{*}$ Liangru Contois, ${ }^{*}$ Leonard Liebes, ${ }^{*}$ Robert Friesel, ${ }^{*}$ Franco Muggia,
} Calvin P.H. Vary, ${ }^{*}$ Leif Oxburgh, ${ }^{*}$ and Peter C. Brooks*

From the Maine Medical Center Research Institute, * Center for Molecular Medicine, Scarborough, Maine; and the New York University Langone Medical Center ${ }^{\dagger}$ Division of Hematology and Medical Oncology, New York, New York

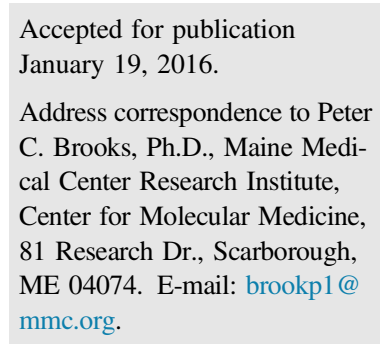

\begin{abstract}
Evidence suggests that stromal cells play critical roles in tumor growth. Uncovering new mechanisms that control stromal cell behavior and their accumulation within tumors may lead to development of more effective treatments. We provide evidence that the HU177 cryptic collagen epitope is selectively generated within human ovarian carcinomas and this collagen epitope plays a role in SKOV-3 ovarian tumor growth in vivo. The ability of the HU177 epitope to regulate SKOV-3 tumor growth depends in part on its ability to modulate stromal cell behavior because targeting this epitope inhibited angiogenesis and, surprisingly, the accumulation of $\alpha$-smooth muscle actin-expressing stromal cells. Integrin $\alpha 10 \beta 1$ can serve as a receptor for the HU177 epitope in $\alpha$-smooth muscle actin-expressing stromal cells and subsequently regulates Erkdependent migration. These findings are consistent with a mechanism by which the generation of the HU177 collagen epitope provides a previously unrecognized $\alpha_{10} \beta_{1}$ ligand that selectively governs angiogenesis and the accumulation of stromal cells, which in turn secrete protumorigenic factors that contribute to ovarian tumor growth. Our findings provide a new mechanistic understanding into the roles by which the HU177 epitope regulates ovarian tumor growth and provide new insight into the clinical results from a phase 1 human clinical study of the monoclonal antibody D93/TRC093 in patients with advanced malignant tumors. (Am J Pathol 2016, 186: 1649-1661; http://dx.doi.org/10.1016/j.ajpath.2016.01.015)
\end{abstract}

The importance of stromal cells, such as endothelial cells, fibroblasts, pericytes, and inflammatory infiltrates, in tumor growth has been appreciated for years. ${ }^{1-4}$ This insight has led investigators to begin developing novel approaches to regulate stromal cell behavior. ${ }^{5-8}$ However, given the functions of stromal cells in normal physiologic processes, it is important to create strategies that might restrict the effect on stromal cells to that within the tumor microenvironment. In this regard, the structures of extracellular matrix (ECM) proteins that compose the architectural framework of most normal tissues are largely intact. In contrast, tumors often exhibit an altered ECM structure with proteolytically degraded matrix proteins. ${ }^{9,10}$ This differential ECM configuration might provide a unique means of selectively regulating stromal cell behavior within tumors because cellular interactions with remodeled or denatured matrix proteins, such as collagen, alters adhesion, migration, proliferation, and survival. ${ }^{11-14}$

Our previous studies uncovered functional cryptic sites within ECM molecules. ${ }^{14-16}$ We have likened the process of generating cryptic elements to that of a biomechanical ECM switch in which structural alterations in these molecules initiated by either proteolytic cleavage or other physical mechanisms lead to the generation of cryptic regulatory epitopes, which contribute to the initiation of unique signaling cascades that facilitate angiogenesis, tumor growth, and metastasis. ${ }^{11-17}$ Recently, we identified a new cryptic ECM epitope present within multiple forms of collagen. ${ }^{15}$ The HU177 epitope was generated within the ECM of angiogenic vessels and regulates endothelial cell

\footnotetext{
Supported by NIH grant CA91645 and Department of Defense grant from the Ovarian Cancer Research Program award W81XWH-13-OCRP-PA (P.C.B.). Additional support was from NIH grants HL65301 (R.F.) and HL083151, American Heart Association grant GRNT20460045 (C.P.H.V.), a Chemotherapy Foundation grant (L.L.), Bioinformatics Core grant P20 RR181789 (D.M.W.), NIH grants 5P30GM103392 (R.F.) and ROIDK078161 (L.O.), and institutional support from the Maine Medical Center.

Disclosures: P.C.B., C.P.H.V., and L.L. hold an equity position in CryptoMedix, LLC.
} 
behavior because a monoclonal antibody (mAb) directed to this epitope selectively inhibited endothelial cell adhesion and migration on denatured collagen and blocked angiogenesis in vivo. ${ }^{15}$ This antibody was humanized (mAb D93/ TRC093) and a phase 1 human clinical trial was completed. ${ }^{18-20}$ Clinical findings suggested that the HU177 epitope plays a role in tumor growth because $26 \%$ of the treated patients exhibited stable disease and a reduction in liver lesions was observed in a patient with ovarian cancer. $^{20}$

Ovarian cancer is a heterogeneous disease classified by distinct histologic subtypes. ${ }^{21-25}$ The molecular complexity of these tumors is indicated by the fact that low-grade type 1 tumors often exhibit alterations in KRAS, BRAF, and PTEN, whereas high-grade type 2 tumors often have alterations in TP53 and BRCA1/2. ${ }^{21-25}$ Importantly, stromal cells, such as endothelial cells and activated fibroblasts, may contribute to the development of ovarian carcinoma. ${ }^{26-28}$ Although collagen remodeling occurs during ovarian tumor growth, it is not known whether these changes are sufficient to generate the HU177 epitope or what role it plays in ovarian tumor growth.

We present evidence that the HU177 cryptic collagen epitope is abundantly generated within human ovarian tumors, whereas little is expressed in benign granulomas. Antibodies directed to this epitope inhibited SKOV-3 tumor growth in vivo, which was accompanied by reductions in proliferation, angiogenesis, and the accumulation of $\alpha$-smooth muscle actin ( $\alpha$-SMA)-expressing stromal cells. Although our studies indicate that the $\alpha_{2} \beta_{1}$ integrin can bind the HU177 site, the little understood integrin $\alpha_{10} \beta_{1}$ plays an important role as a functional receptor in $\alpha$-SMAexpressing stromal cells. Blocking interactions of the HU177 collagen epitope with $\alpha_{10} \beta_{1}$ integrin-expressing fibroblasts reduced fibroblast growth factor (FGF)-2stimulated Erk phosphorylation and migration on denatured collagen. Given the emerging roles of fibroblast-like cells in promoting tumor growth, these findings are consistent with a mechanism by which blocking the HU177 epitope reduces $\alpha_{10} \beta_{1}$-dependent accumulation of $\alpha$-SMA-expressing stromal cells in ovarian tumors, leading to the reduction of an important source of protumorigenic cytokines that contribute to tumor progression.

\section{Materials and Methods}

\section{Reagents, Chemicals, and Antibodies}

Collagen type I was from Sigma (St Louis, MO). Denatured collagen was prepared by boiling the solution of commercially obtained collagen for 15 minutes. The denatured collagen was allowed to cool for 5 minutes before use. FGF-2; integrins $\alpha_{1} \beta_{1}, \alpha_{2} \beta_{1}, \alpha_{3} \beta_{1}, \alpha_{10} \beta_{1}$, and $\alpha_{\mathrm{v}} \beta_{3}$; and antibodies directed to $\alpha_{1}, \alpha_{2}, \alpha_{\mathrm{v}}$ integrins, and IL-6 were from R\&D Systems (Minneapolis, MN). Anti-CD31 antibody was from BD Pharmingen (San Diego, CA).
Anti- $\alpha$-SMA and anti-Ki-67 antibodies were from Abcam (Cambridge, MA). Anti-Erk antibodies were from Cell Signaling Technology (Danvers, MA). Anti-collagen 1 antibody was from Rockland (Gilbertsville, PA). Antibody to $\alpha_{10} \beta_{1}$ was from Novus Biologicals (Littleton, CO). BrdU kit was from Millipore (Bedford, MA). Secondary antibodies were from Promega (Madison, WI). mAb HU177 was developed in our laboratory and found to bind a PGxPG-containing epitopes exposed within denatured but not intact collagen from multiple species. ${ }^{11-16} \mathrm{mAb}$ D93/TRC093 is a humanized version of mAb HU177 that also binds the PGxPG-containing epitopes within denatured collagen from multiple species and was obtained from TRACON (San Diego, CA). The control antibody (mAb XL166) was generated in our laboratory and is directed to an RGD collagen epitope. Synthetic collagen peptide PGF (CPGFPGFC) and control peptides (CQGPSGAPGEC, CTWPRHHTTDALL, and CNSYSYPSLRSP) were from QED Biosciences (San Diego, CA). MEK inhibitor (PD98059) was from CalBiochem (San Diego, CA).

\section{Analysis of Tissue Antigens}

Human ovarian tissues were from Maine Medical Center under institutional review board exempt protocol. For quantification of the HU177 epitope, biopsy specimens $(n=9)$ from high-grade ovarian tumors (serous and endometrial) or benign ovarian granulomas $(n=9)$ were stained with mAb HU177. Ornithine carbamoyltransferase compound-embedded frozen sections $(4.0 \mu \mathrm{m})$ of biopsy specimens of human ovarian tumor tissues were stained by routine hematoxylin and eosin procedure or immunofluorescence. Immunofluorescence staining was performed on frozen sections by first blocking the tissue sections with $1.0 \%$ bovine serum albumin (BSA) in phosphate-buffered saline (PBS) for 1 hour followed by washing three times with PBS. Tissue sections were next incubated with $100 \mu \mathrm{g} / \mathrm{mL}$ of anti-HU177 antibody for 1 hour at room temperature. Tissues sections were next washed three times with PBS followed by incubation with fluorescein isothiocyanate-labeled secondary antibody for 1 hour. For quantification, stained tissue sections were scanned using Kodak ID system and pixel density quantified from five $200 \times$ fields from each of the five specimens from each condition using Molecular Analyst Software version 2.1 (Kodak, Stamford, CT). ${ }^{29}$ Tumors were analyzed for apoptosis using terminal deoxynucleotidyl transferase-mediated dUTP nickend labeling staining, for proliferation using anti-Ki-67 antibody staining (1:1000), for angiogenesis using anti-CD31 antibody staining (1:300), and for carcinoma-associated fibroblast (CAF)-like stromal cells using a combination of anti- $\alpha$-SMA (1:1000), anti-platelet-derived growth factor receptor $\alpha$ (1:500), and anti-fibroblast activation protein (1:300) antibody staining. Quantification was performed within five $200 \times$ fields from each of three to five tumors. 


\section{Cells and Cell Culture}

SKOV-3 cells were from ATCC (Manassas, VA) and cultured in RPMI 1640 medium in the presence of 5\% fetal bovine serum. Human umbilical vein endothelial cells were obtained from Lonza (Walkersville, MD) and cultured in endothelial basal medium 2 in $2 \%$ fetal bovine serum and supplements (Lonza). Human dermal fibroblasts were obtained from Science Cell (Carlsbad, CA) and cultured in medium with $2.0 \%$ fetal bovine serum.

\section{Solid-Phase Binding Assays}

Plates were coated with $25 \mu \mathrm{g} / \mathrm{mL}$ of native or denatured (boiled for 15 minutes) collagen. Collagen epitope peptide PGF and control peptides were immobilized at $100 \mu \mathrm{g} / \mathrm{mL}$. Integrins ( 0 to $2.0 \mu \mathrm{g} / \mathrm{mL}$ ) were diluted in binding buffer that contained $20 \mathrm{mmol} / \mathrm{L}$ Tris, $15 \mathrm{mmol} / \mathrm{L} \mathrm{NaCl}, 1 \mathrm{mmol} / \mathrm{L}$ $\mathrm{MgCl}_{2}, 0.2 \mathrm{mmol} / \mathrm{L} \mathrm{MnCl}_{2}$, and $0.5 \% \mathrm{BSA}$ (pH 7.4) as described. ${ }^{13}$ Integrins were allowed to bind for 1 hour and plates washed and incubated with anti-integrin antibodies (1:100 dilution) for 1 hour. Plates were washed and incubated with horseradish peroxidase-labeled secondary antibodies (1:5000 dilution). In a second assay, $0.5-\mu \mathrm{g} / \mathrm{mL}$ integrins were coated in binding buffer, plates were washed and blocked as before, and 0 to $10.0 \mu \mathrm{g} / \mathrm{mL}$ of denatured (boiled for 15 minutes) collagen was added. Denatured collagen was detected with anticollagen antibody (1:1000). For integrin-blocking enzyme-linked immunosorbent assay, wells were coated with denatured collagen and pretreated with $0.1 \mu \mathrm{g} / \mathrm{mL}$ of antiHU177 or control antibody. After washing, wells were incubated with $2.0-\mu \mathrm{g} / \mathrm{mL}$ integrins, and binding was detected as described. Assays were performed at least three times.

\section{Cell Adhesion Assays}

The wells of nontissue culture 48-well cluster plates were coated for 12 hours at $4^{\circ} \mathrm{C}$ with $5 \mu \mathrm{g} / \mathrm{mL}$ of native or denatured (boiled for 15 minutes) collagen prepared as described above. SKOV-3 and fibroblasts were suspended in adhesion buffer that contained RPMI 1640 medium, $1 \mathrm{mmol} / \mathrm{L} \mathrm{MgCl}_{2}, 0.2 \mathrm{mmol} / \mathrm{L} \mathrm{MnCl}_{2}$, and $0.5 \% \mathrm{BSA}^{13}$ and $1 \times 10^{5}$ cells were added in the presence or absence of 100 $\mu \mathrm{g} / \mathrm{mL}$ of anti-HU177 or control antibodies. Cells were allowed to attach for 25 minutes. Nonattached cells were removed by washing and attached cells stained with crystal violet as described. ${ }^{13}$ Wells were washed and the cellassociated crystal violet was eluted with $100 \mu \mathrm{L}$ per well of $10 \%$ acetic acid. Cell adhesion was quantified by measuring the optical density of the eluted crystal violet as described. ${ }^{15}$ Assays were completed at least three times.

\section{Cell Migration Assays}

Transwell membranes $(8.0-\mu \mathrm{m}$ pore size) were coated with $5 \mu \mathrm{g} / \mathrm{mL}$ of native or denatured collagen for 12 hours at $4^{\circ} \mathrm{C}$ as described previously. ${ }^{13}$ Migration buffer that contained RPMI 1640 medium, $1 \mathrm{mmol} / \mathrm{L} \mathrm{MgCl}_{2}, 0.2 \mathrm{mmol} / \mathrm{L} \mathrm{MnCl}_{2}$, and $0.5 \% \mathrm{BSA}$ in the presence or absence of $5 \times$ concentrated serum free SKOV-3 conditioned medium (CM) or $20 \mathrm{ng} / \mathrm{mL}$ of FGF-2 was placed in the lower chambers. SKOV-3 or fibroblasts $\left(1 \times 10^{5}\right)$ were resuspended in migration buffer that contained RPMI 1640 medium, 1 $\mathrm{mmol} / \mathrm{L} \mathrm{MgCl}_{2}, 0.2 \mathrm{mmol} / \mathrm{L} \mathrm{MnCl}_{2}$, and $0.5 \% \mathrm{BSA}$ in the presence or absence of $10 \mu \mathrm{g} / \mathrm{mL}$ of antibodies directed to the HU177 epitope, $\alpha_{10} \beta_{1}$, or $100 \mu \mathrm{mol} / \mathrm{L}$ of the MEK inhibitor (PD98054). Cells were added to the top chamber and allowed to migrate from 2 to 4 hours. Cells that remained on the top of the membranes were removed, and cells that had migrated to the underside of the membrane were quantified by direct cell counts of crystal violet-stained cells or by measuring the optical density of eluted cell-associated crystal violet dye as previously described. ${ }^{15}$ Assays were completed at least three times.

\section{Cell Proliferation Assays}

To prepare serum free fibroblast CM, $2.0 \times 10^{6}$ cells were seeded in the presence of serum for 2 hours. Serumcontaining medium was removed, cells were washed, and serum free RPMI 1640 medium was added. Serum free medium was collected at 24 hours and concentrated 10-fold. SKOV-3 cells were resuspended in the presence $(150 \mu \mathrm{L})$ of control $(10 \times)$ RPMI 1640 medium or $(10 \times)$ fibroblast CM. Cells were added to wells and allowed to growth for 24 or 72 hours. Cell proliferation was quantified at 24 or 72 hours using BrdU kit according to manufacturer's instructions. Assays were completed three times.

\section{Tumor Growth Assays}

Briefly, chorioallantoic membranes (CAMs) of 10-day-old chicks ( $n=6$ to 8 ) were prepared as described ${ }^{13}$ by separating the CAM from the shell membrane. Single-cell suspensions of SKOV-3 cells $\left(3 \times 10^{6}\right)$ were applied topically to the CAMs in a total volume of $40 \mu \mathrm{L}$. $^{30}$ Twenty-four hours later embryos were either untreated or treated with a single topical application of $100 \mu \mathrm{g}$ of anti-HU177 antibody or control nonspecific antibody (100 $\mu \mathrm{g}$ per embryo) in a total volume of $40 \mu \mathrm{L}$. Tumors were allowed to grow for a total of 7 days. At the end of the 7-day growth period, the embryos were sacrificed, the tumors dissected, and wet weights determined as described previously. ${ }^{13}$ For murine experiments, nude (NCRNU-F) mice ( $n=6$ to 8 ) were injected subcutaneously into the flanks with $3.0 \times 10^{6}$ SKOV-3 cells per mouse. Mice were allowed to form tumors for 5 days and then untreated or injected (i.p.) with 0 to $100 \mu \mathrm{g} / \mathrm{mL}$ of mAb D93 or control antibody three times per week for 28 days. Tumors were measured with calipers and volumes calculated as $\mathrm{V}=\mathrm{L}^{2} \times \mathrm{W} / 2$, where $\mathrm{V}$ indicates volume; L, length; and W, width. Experiments were completed three times. 

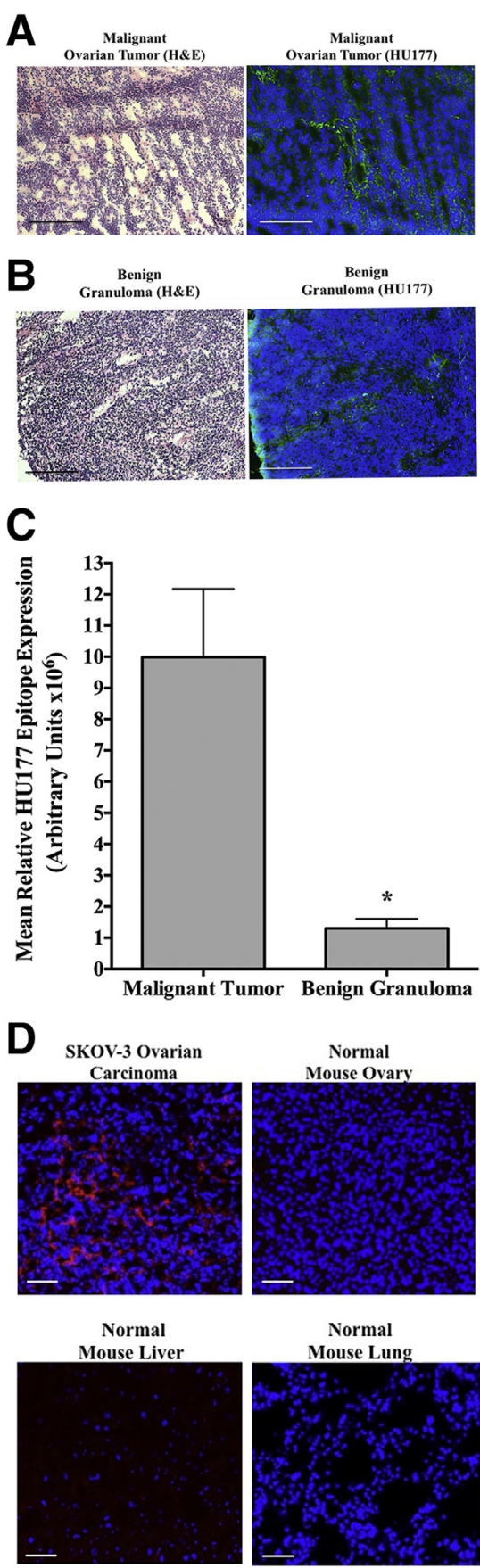

Normal

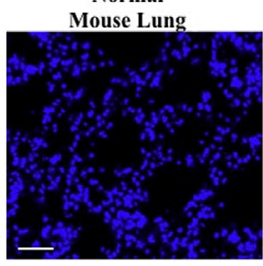

Figure 1 Generation of the HU177 epitope in ovarian tumors. Biopsy specimens from frozen sections of malignant human ovarian tumors or benign granulomas were stained with hematoxylin and eosin (H\&E) or with anti-HU177 antibody. Examples of H\&E staining or staining for the HU177 cryptic collagen epitope in malignant ovarian tumors (A) or benign granulomas (B). C: Quantification of the relative levels of HU177 epitope within malignant ovarian tumors or benign granulomas. D: Examples of HU177 epitope (red) within SKOV-3 tumors or normal ovaries, lungs, and liver. Data are expressed as means \pm SEM from five fields $(\mathbf{C}) .{ }^{*} P<0.05$ compared with controls. Scale bars $=63 \mu \mathrm{m}$. Original magnification, $\times 200$.

\section{Western Blot Analysis}

Cells from culture or cells seeded on native or denatured (boiled for 15 minutes) collagen type I-coated plates were allowed to attach for 15 minutes, then they were lyzed in radioimmunoprecipitation assay buffer (Santa Cruz, CA) with $1 \times$ protease inhibitor cocktail. Lysates were separated by SDS-PAGE and probed with antibodies directed to $\alpha_{10}, \alpha_{1}$ integrins, total and phosphorylated Erk, Ki-67, $\beta$-tubulin, or actin. Assays were performed at least three times.

\section{Cytokine Analysis of Fibroblast CM}

A total of $50 \mu \mathrm{L}$ of serum free $\mathrm{CM}$ was screened for a panel of 12 cytokines (IL- $1 \alpha$, IL-1 $\beta$, IL-2, IL-4, IL-6, IL-8, IL-10, IL-12, IL-17A, tumor necrosis factor- $\alpha$, interferon- $\gamma$, and granulocyte-macrophage colony-stimulating factor) using the Multi-analyte ELISArray kit (Qiagen, Valencia, CA) according to the manufacturer's instructions. Analysis of conditioned medium was completed twice.

\section{Statistical Analysis}

Statistical analysis was performed using Graph Pad Instat for Mac version 3.0b (Graphpad Software Inc, La Jolla, CA). Data were analyzed for significance using the $t$-test. $P<0.05$ was considered significant.

\section{Results}

\section{Differential Generation of the HU177 Epitope in Ovarian Tumors}

Studies have correlated enhanced collagen synthesis and ECM degradation with tumor progression. ${ }^{31,32}$ In this regard, we examined biopsy specimens of human ovarian tumors and benign granulomas for expression of the HU177 cryptic collagen epitope. Serial sections from frozen tissues were stained by hematoxylin and eosin or with anti-HU177 antibody. The HU177 cryptic collagen epitope (green) could be detected in the ECM of malignant ovarian tumors (Figure 1A), whereas minimal detection was observed in the ECM of the benign ovarian lesions (Figure 1B). Quantification of the relative levels of the HU177 cryptic collagen epitope (Figure $1 \mathrm{C})$ indicated a significant $(P<0.05)$ increase in HU177 collagen epitope in tumors compared with the benign lesions. To confirm the generation of the HU177 epitope in an experimental mouse model, we examined its expression of the HU177 collagen epitope in SKOV-3 tumors growing in mice. Although HU177 epitope was detected within the SKOV-3 tumors, little was observed in normal tissues, including ovaries, liver, and lungs (Figure 1D). These findings are consistent with the restricted generation of the collagen epitope.

\section{The HU177 Epitope Regulates Ovarian Tumor Growth}

Given the differential generation of the HU177 epitope observed in vivo, we determined whether the HU177 epitope plays a functional role in ovarian tumor growth. To examine this possibility, SKOV-3 ovarian tumor cells were seeded topically 

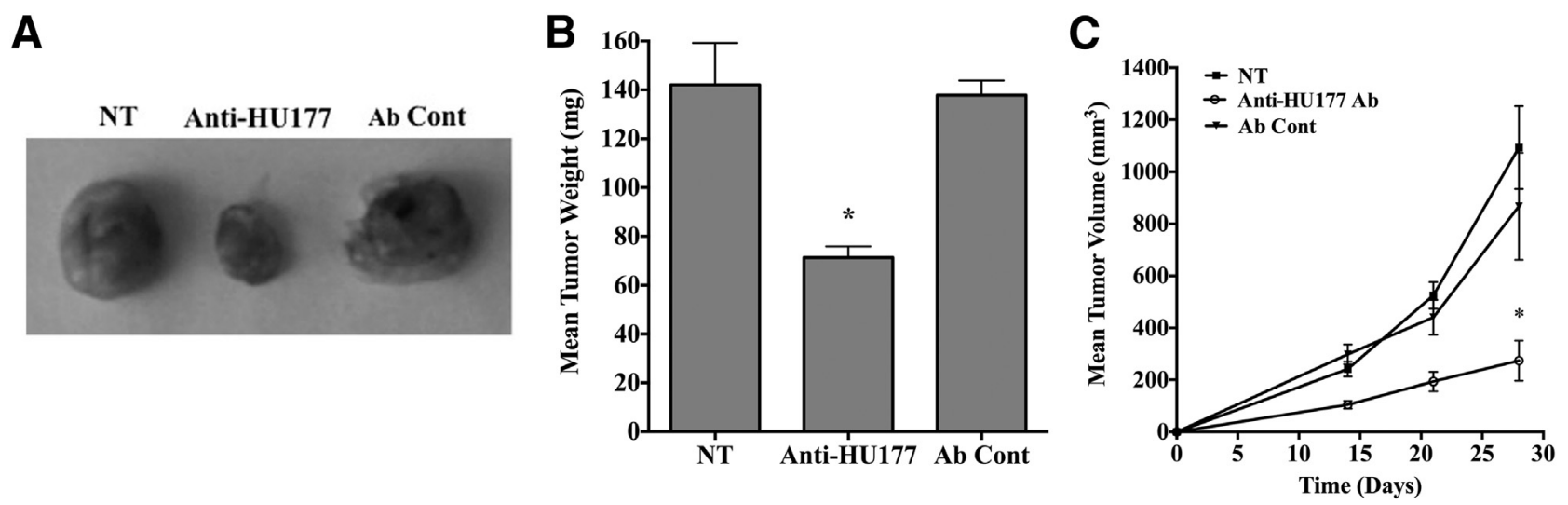

Figure 2 Inhibition of tumor growth by targeting the HU177 epitope. A and B: SKOV-3 cells were seeded topically on the chorioallantoic membranes of chick embryos. Twenty-four hours later, the animals were not treated (NT) or treated once topically with $100 \mu \mathrm{g}$ of anti-HU177 or $100 \mu \mathrm{g}$ of control antibody (Ab Cont). A: Examples of tumors from each condition. B: Quantification of mean tumor weights from each condition after a 7-day incubation period. C: Mice were injected s.c. in the flanks with SKOV-3 cells and 5 days later were untreated or treated i.p. with $100 \mu \mathrm{g}$ of anti-HU177 antibody or Ab Cont three times per week for 28 days. Data are expressed as means \pm SEM of tumor weights (B) and tumor volume (C). $n=7$ to 8 animals per condition (B); $n=5$ to 6 animals per condition (C). ${ }^{*} P<0.05$ compared with controls.

on the CAM of chick embryos. Twenty-four hours later the embryos were either not treated or treated with a single topical application with anti-HU177 antibody or nonspecific control. After 7 days of incubation, the resulting tumors were dissected from the CAMs for analysis. SKOV-3 tumors dissected from chick embryos treated with anti-HU177 antibody were smaller than controls (Figure 2A). Quantification indicated that targeting the HU177 epitope significantly $(P<0.05)$ inhibited SKOV-3 tumor growth by approximately $50 \%$ compared with controls (Figure 2B). To confirm these findings in a murine model, SKOV-3 cells were injected subcutaneously into the flanks of nude mice. Five days after establishment of small tumor lesions, mice were either untreated or treated $(100 \mu \mathrm{g}$ per mouse three times per week) i.p. with anti-HU177 mAb or control nonspecific antibody. Treatment with anti-HU177 antibody significantly $(P<0.05)$ reduced tumor size by approximately $70 \%$ by day 28 (Figure $2 \mathrm{C}$ ). Dose-dependent studies indicated inhibition of tumor growth at doses of antiHU177 antibody as low as $10 \mu \mathrm{g}$ per mouse three times per week (data not shown).

\section{The HU177 Epitope Regulates Angiogenesis and Stromal Cell Accumulation in Ovarian Tumors}

The behavior of multiple cell types within the tumor microenvironment, including stromal cells, can be controlled by interactions with collagen. ${ }^{2,6,33-37}$ Therefore, we examined apoptosis within control and anti-HU177-treated SKOV-3 tumors using terminal deoxynucleotidyl transferasemediated dUTP nick-end labeling staining. An approximately 1.8 -fold increase in apoptosis was detected within anti-HU177-treated tumors compared with control (data not shown); however, because of variation in staining, this increase did not meet statistical significance. Next, we examined cellular proliferation by quantifying Ki-67 antigen expression within these tumors growing in vivo.
SKOV-3 tumors from anti-HU177 $\mathrm{mAb}-$ treated mice exhibited significantly $(P<0.05)$ reduced $(25 \%$ to $40 \%)$ Ki-67 expression compared with no treatment or control antibody, respectively (Figure 3A). Given previous studies indicating that blocking the HU177 epitope selectively inhibited endothelial cell adhesion to denatured collagen type IV but not native intact collagen type $\mathrm{IV}^{15}$ and inhibited angiogenesis in vivo, ${ }^{15,18}$ the reduction in cellular proliferation within these tumors could be due to multiple mechanisms, including inhibition of angiogenesis given the known role of angiogenesis in regulating tumor growth.

To examine the distribution of the HU177 epitope in ovarian tumors, SKOV-3 tumors were co-stained with antibodies directed to the HUI77 epitope and CD31, a marker of blood vessels. Although the HU177 epitope was detected in association with some CD31-positive vessels (Figure 3B), it was more extensively associated with $\alpha$-SMA-expressing fibroblast-like stromal cells (Figure 3B). Given the close proximity of the $\alpha$-SMA-expressing stromal cells and blood vessels to the HU177 epitope, it is possible that $\alpha$-SMA-expressing stromal cells and endothelial cells may interact with this cryptic collagen epitope and regulate their behavior. Therefore, we analyzed the effects of anti-HU177 $\mathrm{mAb}$ treatment on SKOV-3 tumor angiogenesis and the accumulation of tumor-associated $\alpha$-SMA-expressing cells. A significant $(P<0.05) 35 \%$ inhibition of SKOV-3 ovarian tumor angiogenesis was observed, and remarkably (Figure 3C), a 70\% reduction in $\alpha$-SMA-expressing stromal cells was also detected after treatment with anti-HU177 antibody (Figure 3D), consistent with a possible role for cellular interactions with the HU177 epitope in regulating accumulation of these cells within the tumor. Collectively, these findings are consistent with the notion that reduced angiogenesis and $\alpha$-SMA-expressing stromal cell accumulation may contribute to the anti-tumor activity observed after selective blockade of the HU177 collagen epitope. 
A

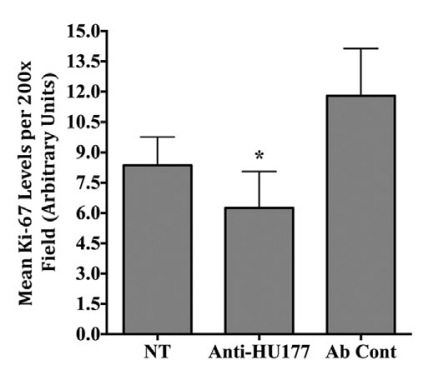

B
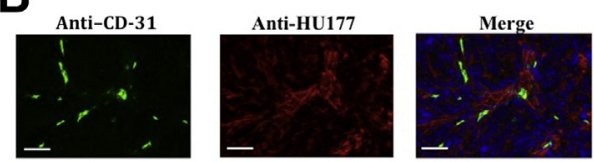

Anti- $\alpha$-SMA
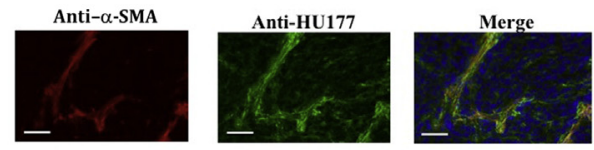

D
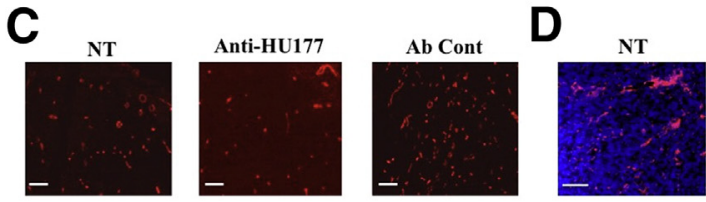

Figure 3 Analysis of SKOV-3 tumors growing in mice. Mice were injected s.c. in the flanks with SKOV-3 cells and after a 5-day incubation period were not treated (NT) or treated i.p. with $100 \mu \mathrm{g}$ of anti-HU177 or $100 \mu \mathrm{g}$ of control antibodies (Ab Cont) three times per week for 28 days. A: Analysis of the relative levels of $\mathrm{Ki}-67$ expression per $200 \times$ field in SKOV-3 tumors. B: Example of co-expression of CD31 (green) and HU177 epitope (red) in untreated SKOV-3 tumors and co-expression of $\alpha$-smooth muscle actin ( $\alpha$-SMA) (red) and HU177 epitope (green) in untreated SKOV-3 tumors. C: Mice were injected s.c. in the flanks with SKOV-3 cells and after a 5-day incubation period were either untreated or treated i.p. with $100 \mu \mathrm{g}$ of anti-HU177 or Ab Cont three times per week for 28 days. Examples of tumors from each condition stained for CD31 (red) and the quantification of tumor angiogenesis per $100 \times$ field. D: Mice were injected subcutaneously in the flanks with SKOV-3 cells and after a 5-day incubation period were either untreated or treated i.p. with $100 \mu \mathrm{g}$ of anti-HU177 or Ab Cont three times per week for 28 days. Examples of tumors from each condition stained for $\alpha$-SMA (red) and the quantification $\alpha$-SMA-expressing infiltrating stromal cells per $100 \times$ field. Data are expressed as means \pm SEM $(\mathbf{A}, \mathbf{C}$, and $\mathbf{D})$. ${ }^{*} P<0.05$ compared with controls. Scale bars $=126 \mu \mathrm{m}$.

\section{SKOV-3 Tumor Cells and Fibroblast Exhibit Enhanced Adhesion and Migration on Denatured Collagen}

Previous studies have documented that changes in the native structure of ECM proteins can alter the ability of cells to bind to these denatured proteins in part by disrupting conformational dependent epitopes required for cell binding in the context of its native configuration and/or exposing previously hidden cryptic binding epitopes, including cryptic arginine-glycine-aspartic acid-containing sequences. ${ }^{12-16}$ However, the ability of distinct cell types to interact with denatured collagen may vary widely and likely depends on multiple factors, including the expression and activation of cell surface receptors with the capacity to recognize and bind to the multiple cryptic epitopes exposed after denaturation. To examine whether cellular interactions with denatured collagen alter cellular behavior, we compared SKOV-3 and fibroblast adhesion and migration on native and denatured collagen. A small but significant $(P<0.05)$ enhancement of SKOV-3 (38\%) and fibroblast (29\%) adhesion was detected on denatured collagen compared with native collagen (Figure 4, A and B). In similar studies, we compared the basal migratory capacity of SKOV-3 and fibroblasts on native and denatured collagen. Again a small but significant $(P<0.05)$ enhancement of SKOV-3 (34\%) and fibroblast (19\%) migration was detected on denatured collagen compared with native collagen (Figure 4, C and D). Although these studies do not specifically indicate that the enhanced adhesion and migration of the cells on denatured collagen depend specifically on the HU177 epitope, given that multiple cryptic epitopes are exposed after denaturation, these observations, however, indicate that interactions with
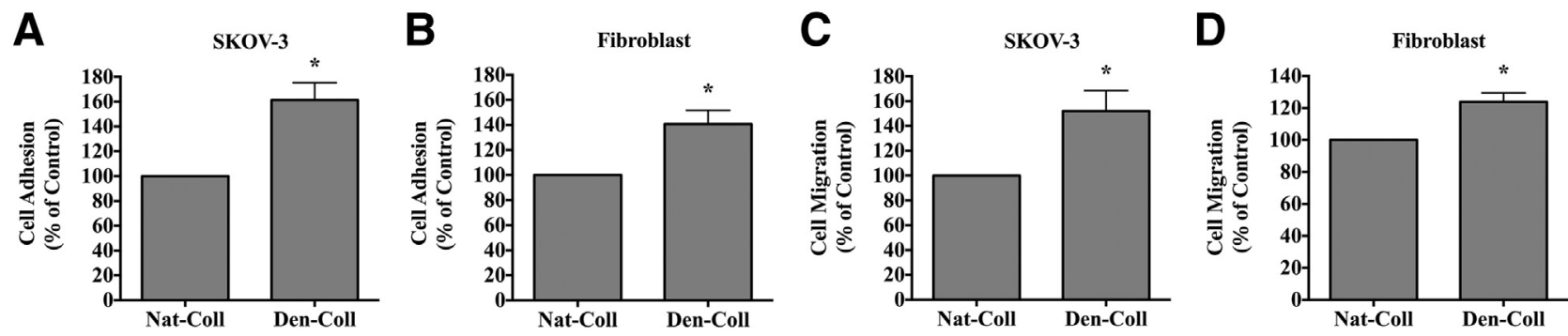

Figure 4 SKOV-3 tumor cells and fibroblast exhibit enhanced adhesion and migration on denatured collagen. Nontissue culture wells and membranes from transwell migration chambers were coated with $5.0 \mu \mathrm{g} / \mathrm{mL}$ of native collagen (Nat-Coll) or denatured collagen (Den-Coll). SKOV-3 cells (A and C) or fibroblasts (B and D) were allowed to attach or migrate on either native or denatured collagen. A: Quantification of mean SKOV-3 cell adhesion. B: Quantification of mean fibroblast cell adhesion. C: Quantification of mean SKOV-3 cell migration. D: Quantification of mean fibroblast cell migration. Data are expressed as means \pm SEM of cell adhesion expressed as a percentage of control with adhesion on native collagen set at $100 \%(\mathbf{A}-\mathbf{D}) . n=4(\mathbf{A}, \mathbf{B}$, and $\mathbf{D}) ; n=3(\mathbf{C})$. ${ }^{*} P<0.05$ compared with controls. 

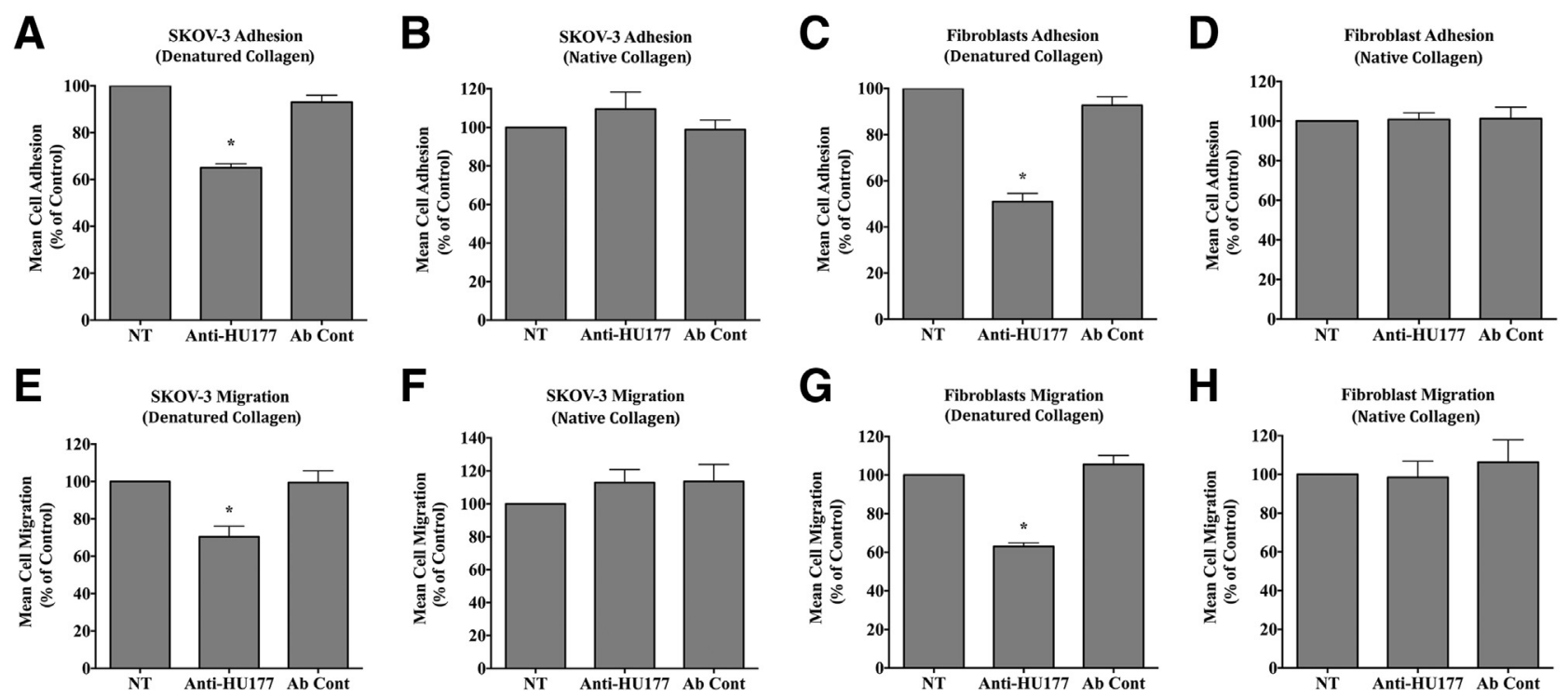

Figure 5 Blocking the HU177 epitope inhibits basal adhesion and migration on denatured collagen. Nontissue culture wells and membranes from transwell migration chambers were coated with $5.0 \mu \mathrm{g} / \mathrm{mL}$ of native collagen or denatured collagen. SKOV-3 cells $(\mathbf{A}, \mathbf{B}, \mathbf{E}$, and $\mathbf{F})$ or fibroblasts $(\mathbf{C}, \mathbf{D}, \mathbf{G}$, and $\mathbf{H})$ were allowed to attach or migrate on either native or denatured collagen in the presence or absence of $50 \mu \mathrm{g} / \mathrm{mL}$ of anti-HU177 antibody or control antibody (Ab Cont). A and B: Quantification of SKOV-3 cell adhesion to denatured or native collagen in the presence or absence of anti-HU177 or Ab Cont. C and D: Quantification of fibroblast cell adhesion to denatured or native collagen in the presence or absence of anti-HU177 or Ab Cont. E and F: Quantification of SKOV-3 cell migration on denatured or native collagen in the presence or absence of anti-HU177 or Ab Cont. G and H: Quantification of fibroblast cell migration on denatured or native collagen in the presence or absence of anti-HU177 or Ab Cont. Data are expressed as means \pm SEM of cell adhesion indicated as a percentage of control with no treatment set at $100 \%(\mathbf{A}-\mathbf{D})$ or as means \pm SEM of mean cell migration indicated as a percentage of control $(\mathbf{E}-\mathbf{H}) . n=4$ to 5 $(\mathbf{A}$ and $\mathbf{B}) ; n=3$ to 7 ( $\mathbf{C}$ and $\mathbf{D}) ; n=4(\mathbf{E}$ and $\mathbf{F}) ; n=3$ to $4(\mathbf{G}$ and $\mathbf{H}) .{ }^{*} P<0.05$ compared with controls. NT, not treated.

denatured collagen can alter the behavior of SKOV-3 cells and fibroblasts in vitro.

\section{The HU177 Epitope Regulates SKOV-3 and Fibroblast Adhesion and Migration on Denatured Collagen}

Tumor and fibroblast adhesive interactions with denatured collagen, which are present within the microenvironment of malignant cancers, may regulate tumor progression. Given our studies indicating that denaturation of collagen can alter the adhesive and migratory behavior of SKOV-3 cells and fibroblasts, we examined the role of the HU177 collagen epitope on regulating adhesion and migration of these cells. Selectively blocking the HU177 epitope exposed within denatured collagen significantly $(P<0.05)$ inhibited adhesion of SKOV-3 cells to denatured collagen by approximately 40\% (Figure 5A). In contrast, the anti-HU177 antibody failed to inhibit adhesion to intact collagen (Figure 5B). These data are consistent with previous studies that report a selective inhibition of cellular interactions with denatured collagen given that the anti-HU177 antibody does not bind native intact collagen. ${ }^{15-18}$ In similar studies, we examined the effects of targeting the HU177 epitope on fibroblast adhesion to denatured collagen. Similar to what was observed with SKOV-3 tumor cells, blocking the HU177 epitope significantly $(P<0.05)$ inhibited fibroblast adhesion to denatured collagen by approximately 50\% compared with controls, whereas this antibody had no effect on fibroblast adhesion on native intact collagen (Figure 5, C and D). These data indicate that the ability of the anti-HU177 antibody to inhibit adhesion is restricted to those circumstances in which the HU177 epitope is generated; thus, the anti-HU177 antibody does not alter adhesion to intact collagen, thereby allowing a highly selective strategy to inhibit adhesive cellular interactions with denatured collagen.

Next, we examined the migratory capacity of these cells on native and denatured collagen. Blocking the HU177 epitope exposed within denatured collagen also significantly $(P<0.05)$ inhibited basal migration of SKOV-3 and fibroblasts by $35 \%$ to $38 \%$ (Figure 5, E and F), whereas migration on intact collagen was not effected (Figure 5, E-H). Interestingly, although blocking the HU177 epitope inhibited adhesion and migration, it exhibited little effect on the growth of SKOV-3 cells or fibroblasts on denatured collagen when examined in vitro (data not shown). These studies are consistent with the anti-HU177 antibody having minimal if any direct antiproliferative activity on fibroblasts or SKOV-3 cells on denatured collagen in vitro.

\section{Inhibition of Growth Factor-Induced Fibroblast Migration by Targeting the HU177 Epitope}

Accumulating evidence indicates that recruitment of activated and/or cancer-associated fibroblasts may facilitate tumor growth and survival, in part by providing an important source of protumorigenic factors, including IL-6. 2,5,6,38 Although it is clear that most dermal fibroblast do not represent a fully accurate model of cancer-associated stromal cells 
A

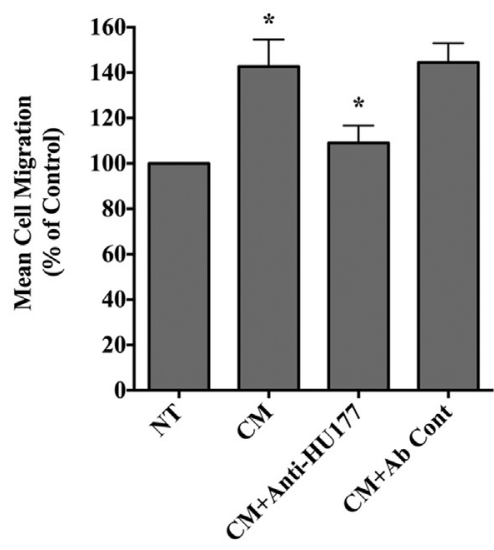

B

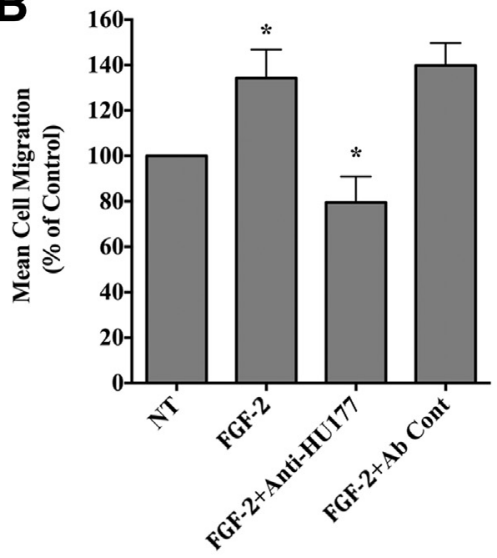

C

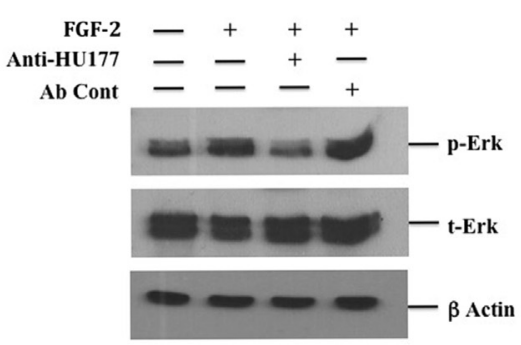

D

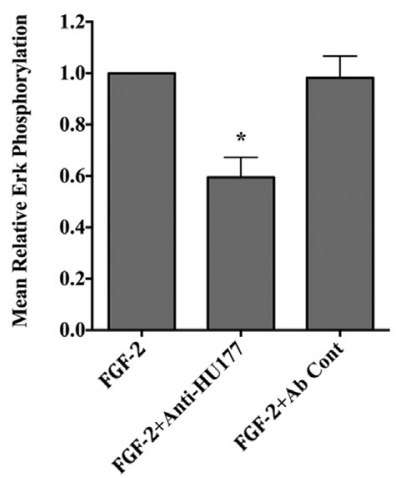

E

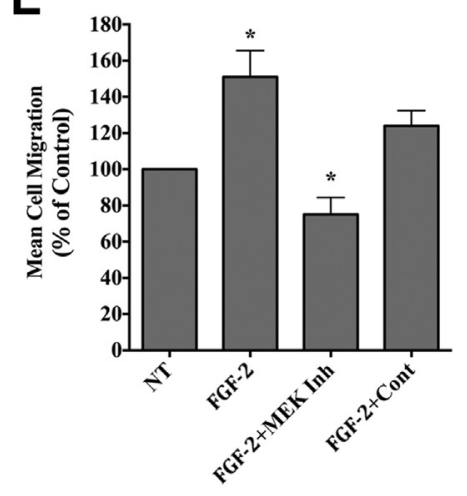

Figure 6 Targeting the HU177 epitope inhibits growth factor-induced migration and Erk phosphorylation. Fibroblasts were resuspended in the presence or absence of SKOV-3 CM (A) or fibroblast growth factor (FGF)-2 (B) in the presence or absence of $50 \mu \mathrm{g} / \mathrm{mL}$ of anti-HU177 or control antibodies (Ab Cont). A and B: Quantification of fibroblast cell migration on denatured collagen. C: Western blot analysis of Erk in lysates from fibroblasts seeded on denatured collagen in the presence or absence of $50 \mu \mathrm{g} / \mathrm{mL}$ of anti-HU177 or Ab Cont. D: Quantification of mean FGF-2-induced Erk phosphorylation in the presence or absence of anti-HU177 antibody or Ab Cont from fibroblasts seeded on denatured collagen. E: Fibroblasts were resuspended in the presence or absence of FGF-2 and in the presence or absence of Mek inhibitor and allowed to migrate on denatured collagen. Data are expressed as means \pm SEM of migration indicated as a percentage of control (A, B, and E). $n=3(\mathbf{A}, \mathbf{B}$, and $\mathbf{E}) .{ }^{*} P<0.05$ compared with controls. CM, conditioned medium; NT, not treated.

found in vivo, following in vitro culture, our fibroblasts exhibited phosphorylated Erk and expressed $\alpha$-SMA and platelet-derived growth factor receptor $\alpha$, important markers of CAF-like stromal cells (data not shown). Therefore, we used these fibroblasts as a model of $\alpha$-SMA-expressing stromal cells and examined whether blocking the HU177 epitope could alter growth factor-induced migration. Concentrated SKOV-3 CM and recombinant FGF-2 stimulation enhanced migration on denatured collagen (Figure 6, A and B). Importantly, addition of the anti-HU177 antibody to the migration wells significantly $(P<0.05)$ inhibited this growth factorstimulated response, suggesting that not only can the HU177 epitope play a role in the basal cell migration but also that it can help regulate growth factor-mediated motility.

Previous studies have indicated that FGF-2 stimulation can initiate a complex signaling cascade, leading to the phosphorylation of multiple effector molecules and transcription factors, such as Erk1/2, which help coordinate the complex events required for cellular migration. ${ }^{39-44}$ Given the known role of FGF-2 in regulating Erk activation, we examined the effects of blocking fibroblast interactions with the HU177 epitope on FGF-2-stimulated Erk phosphorylation. FGF-2 stimulated a small increase in Erk phosphorylation in cells attached to denatured collagen, whereas blocking the HU177 epitope reduced this phosphorylation (Figure 6C). A mean reduction in Erk phosphorylation from four independent experiments of approximately $40 \%$ was observed (Figure 6D). To confirm a role for MAP/Erk signaling in FGF2-stimulated fibroblast motility on denatured collagen, migration assays were performed in the presence of a MEK inhibitor. Addition of the MEK inhibitor (PD98059) significantly $(P<0.05)$ blocked FGF-2-stimulated migration on denatured collagen, suggesting a role for MAP/Erk signaling in regulating this migratory response (Figure 6E).

\section{Identification of Receptors for the HU177 Epitope}

We previously identified the repetitive PGxPG-containing sequence as a critical component of the HU177 epitope. ${ }^{15}$ In addition, other studies have indicated that antibodies directed to the HU177 epitope can bind to a variety of distinct PGxPG-containing sequences with different 

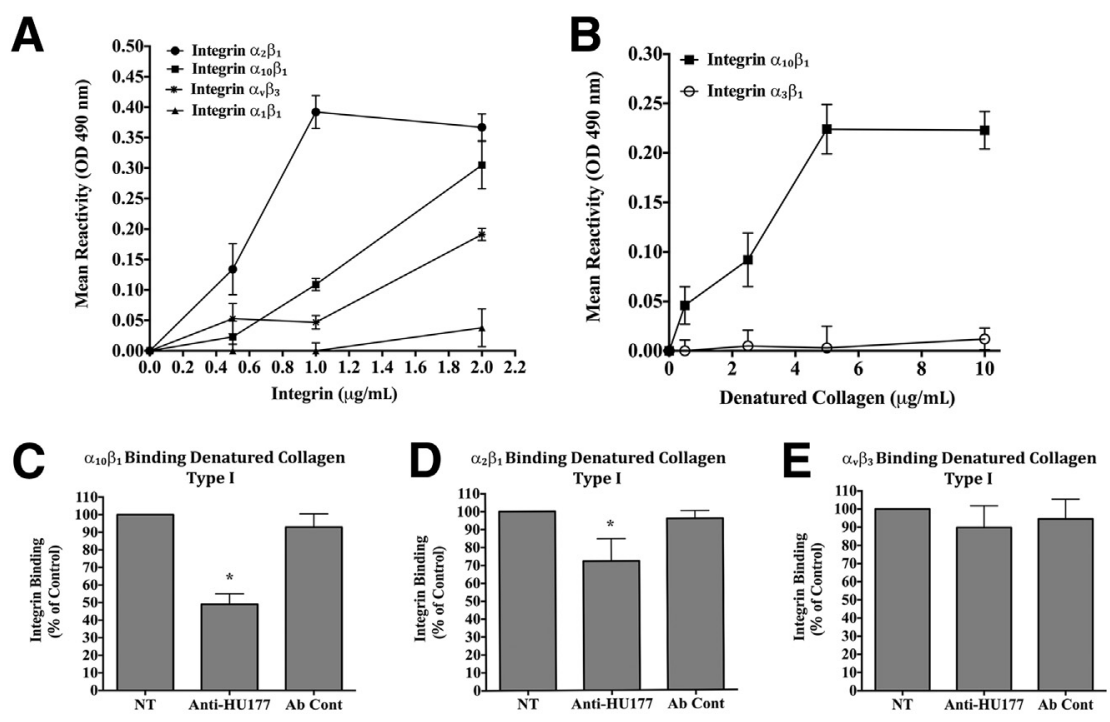

\section{$\mathbf{F}$}
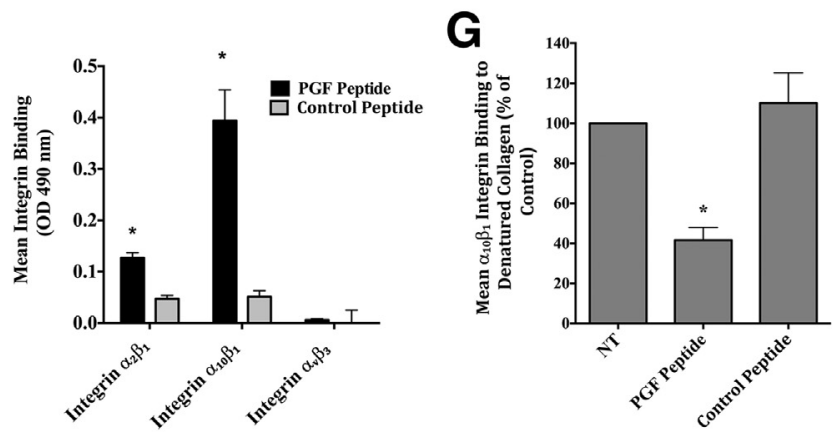

Figure 7 Integrin $\alpha_{10} \beta_{1}$ binds the HU177 collagen epitope. Wells were coated with denatured collagen $(\mathbf{A}, \mathbf{C}-\mathbf{E})$, integrins $\alpha_{10} \beta_{1}$ and $\alpha_{3} \beta_{1}$ (B), or the synthetic HU177 epitope peptide or control peptide $(\mathbf{F})$ and integrins $(\mathbf{A}, \mathbf{C}-\mathbf{E})$ or denatured collagen (B) and allowed to bind. A: Integrin binding to denatured collagen. B: Binding of denatured collagen to immobilized integrins. C: Binding of $\alpha_{10} \beta_{1}$ to denatured collagen in the presence or absence of anti-HU177 or control antibodies (Ab Cont). D: Binding of $\alpha_{2} \beta_{1}$ to denatured collagen in the presence or absence of anti-HU177 or Ab Cont. E: Binding of $\alpha_{v} \beta_{3}$ to denatured collagen in the presence or absence of anti-HU177 or Ab Cont. F: Integrin binding to synthetic HU177 epitope or control peptide. G: Integrin binding to denatured collagen in the presence of synthetic HU177 epitope or control peptide. Experiments were completed at least three times. ${ }^{*} P<0.05$ compared with controls. NT, not treated; OD, optical density.
$\mathrm{N}$-terminal and C-terminal flanking sequences found in collagen. ${ }^{19}$ Given that a number of variations of this motif are found throughout collagen, it is possible that multiple receptors may have the ability to bind to these cryptic sites. To this end, integrin receptors are an important class of molecules known to mediate cellular interactions with ECM components and coordinate signaling cascades that govern cell motility. To define potential cell surface receptors for HU177 collagen epitope, we examined the ability of various recombinant integrins to bind denatured collagen. Integrin $\alpha_{2} \beta_{1}$ and $\alpha_{\mathrm{v}} \beta_{3}$ dose-dependently bound denatured collagen, whereas $\alpha_{1} \beta_{1}$ caused minimal interactions (Figure 7A). Interestingly, integrin $\alpha_{10} \beta_{1}$, a collagen-binding receptor with a limited tissue distribution outside of cartilage, ${ }^{45-48}$ also dose-dependently bound denatured collagen. To confirm $\alpha_{10} \beta_{1}$ binding to denatured collagen, we performed a second binding assay by immobilizing $\alpha_{10} \beta_{1}$ on microliter wells and examining soluble denatured collagen binding. Denatured collagen dose-dependently bound $\alpha_{10} \beta_{1}$ but not $\alpha_{3} \beta_{1}$ (Figure 7B). To identify which integrins capable of binding denatured collagen have the ability to bind the HU177 epitope, we examined the effects of blocking the HU177 epitope on integrin binding. Blocking the HU177 epitope inhibited $\alpha_{10} \beta_{1}$ binding by nearly $60 \%$ (Figure 7C), whereas $\alpha_{2} \beta_{1}$ binding was reduced by approximately $30 \%$ (Figure 7D). Binding of $\alpha_{\mathrm{v}} \beta_{3}$ to denatured collagen was unaffected (Figure 7E). To confirm the integrin-binding specificity, direct binding to the synthetic PGxPGcontaining HU177 epitope (PGF peptide) was performed. Although $\alpha_{2} \beta_{1}$ bound the HU177 epitope, $\alpha_{10} \beta_{1}$ exhibited fourfold greater binding, whereas $\alpha_{\mathrm{v}} \beta_{3}$ failed to bind (Figure 7F). Moreover, the PGF peptide also partially competed binding of $\alpha_{10} \beta_{1}$ to denatured collagen by approximately $60 \%$ (Figure $7 \mathrm{G}$ ). Taken together, these findings suggest that the little understood integrin $\alpha_{10} \beta_{1}$ can bind the HU177 collagen epitope.

\section{Integrin $\alpha_{10} \beta_{1}$ Co-Localizes with $\alpha$-SMA-Expressing Cells in Ovarian Tumors}

Given our studies indicating the ability of $\alpha_{10} \beta_{1}$ to bind the HU177 epitope, we examined the expression of $\alpha_{10} \beta_{1}$ within ovarian tumors. $\alpha_{10} \beta_{1}$ was detected within human ovarian tumors and SKOV-3 tumors (Figure 8A). Expression of $\alpha_{10} \beta_{1}$ was associated predominately with $\alpha$-SMA-positive cells as suggested by extensive co-localization (Figure 8B). Although minimal levels of $\alpha_{10}$ integrin protein (Figure 8 C) and mRNA (data not shown) were detected in SKOV-3 cells, greater than fivefold higher levels were detected in $\alpha$-SMAexpressing fibroblasts. We next examined the effects of blocking $\alpha_{10} \beta_{1}$ on fibroblast migration. Anti- $\alpha_{10}$ antibody inhibited FGF-2-stimulated migration on denatured collagen (Figure 8D). To confirm a role for $\alpha_{10} \beta_{1}$ integrin in fibroblast migration on denatured collagen, we knocked down 


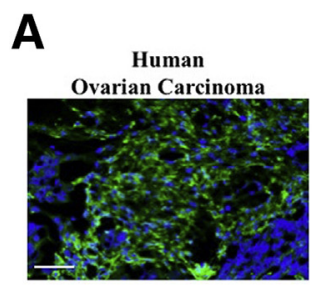

D
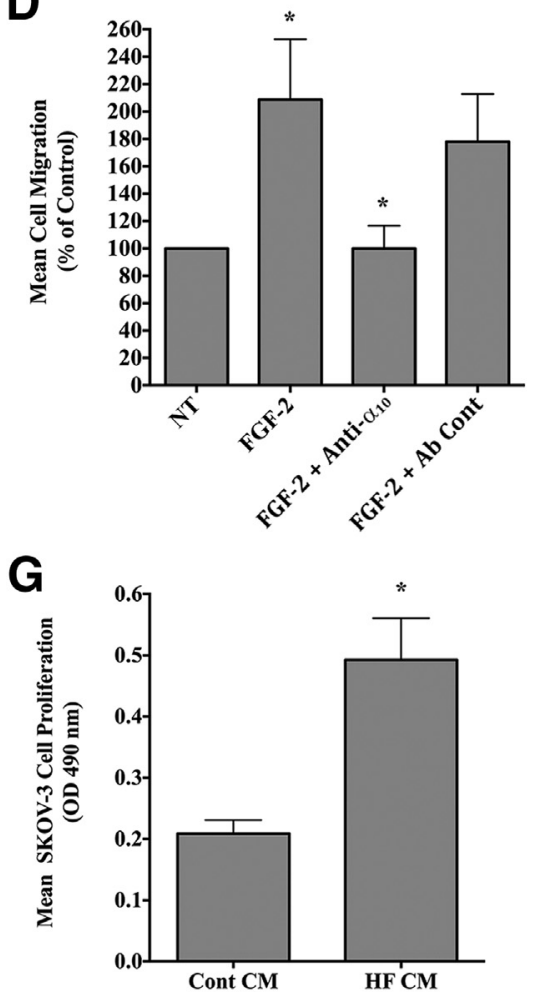

B

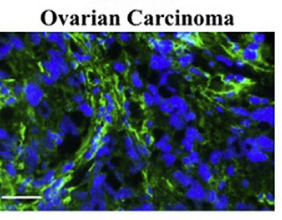

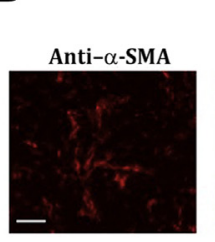

E

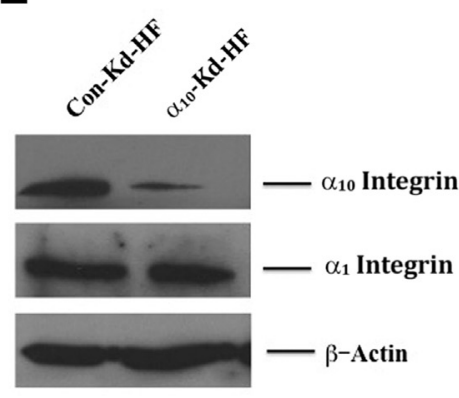

C

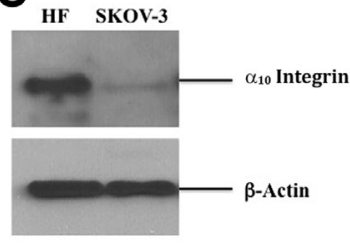

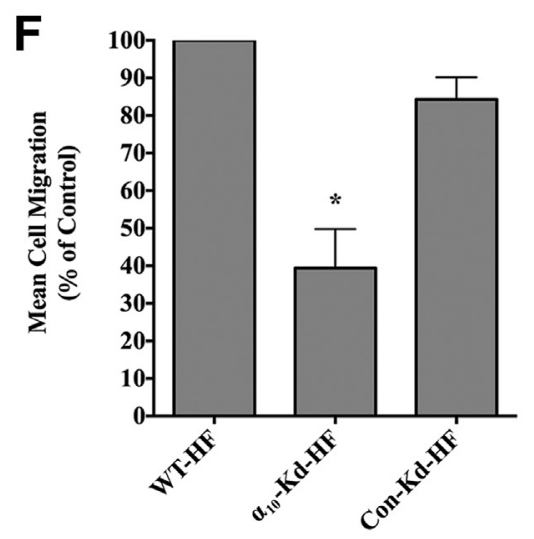

H

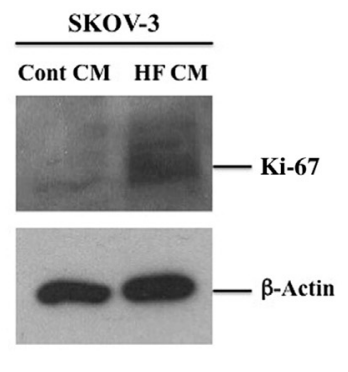

I

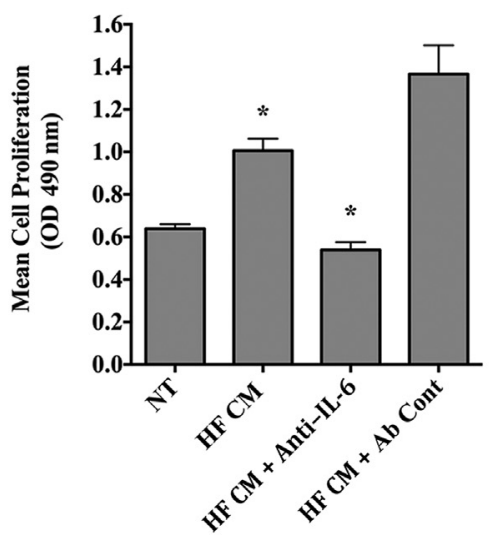

Figure 8 Expression and migratory function of $\alpha_{10} \beta_{1}$. A: Example of expression of $\alpha_{10} \beta_{1}$ (green) in human ovarian tumor biopsy specimen and SKOV-3 tumors. B: Example of co-expression of $\alpha_{10} \beta_{1}$ (green) and $\alpha$-smooth muscle actin ( $\alpha$-SMA) (red)-expressing stromal cells within SKOV-3 tumors. C: Analysis of $\alpha_{10} \beta_{1}$ expression in SKOV-3 cells or fibroblasts (HF) by Western blot. D: Quantification of fibroblast growth factor (FGF)-2-induced fibroblasts migration in the presence or absence of anti- $\alpha_{10} \beta_{1}$ antibody or antibody control (Ab Cont). E: Western blot analysis of relative expression of $\alpha_{10}$ integrin, $\alpha_{1}$ integrin, or $\beta$-actin in cell lysates from nonspecific control knockdown fibroblasts (Con-Kd-HF) or $\alpha_{10}$ integrin knockdown fibroblasts ( $\alpha_{10}$-Kd-HF). F: Quantification of FGF2 -induced migration of wild-type (WT-HF), $\alpha_{10}$ integrin knockdown fibroblasts ( $\alpha_{10}-\mathrm{Kd}-\mathrm{HF}$ ), or nonspecific control knockdown fibroblasts (Con-Kd-HF) on denatured collagen. G: SKOV-3 cell proliferation in the presence of control or fibroblast conditioned medium (CM). H: Western blot analysis for Ki-67 in lysates of SKOV-3 cells treated with fibroblast CM. I: SKOV-3 proliferation in the presence or absence of fibroblast CM and in the presence of anti-IL- 6 or control antibodies. All experiments were completed at least three times with similar results. Data are expressed as means \pm SEM. $n=3(\mathbf{D}$ and $\mathbf{F})$. ${ }^{\star} P<0.05$ compared with controls. Scale bars $=63 \mu \mathrm{m}$. Original magnification, $\times 200$ (B). NT, not treated.

expression $\alpha_{10} \beta_{1}$ integrin in these fibroblasts using $\alpha_{10^{-}}$ specific shRNA. The relative levels of $\alpha_{10}$ protein were reduced by approximately $70 \%$, whereas little change in $\alpha_{1}$ integrin chain or actin was observed (Figure $8 \mathrm{E}$ ). Next, we examined the ability of fibroblasts expressing altered levels of $\alpha_{10}$ integrin to migrate on denatured collagen. Although little if any change was observed in control transfected fibroblasts compared with wild-type parental cells, knocking down $\alpha_{10}$ integrin significantly $(P<0.05)$ inhibited fibroblast migration on denatured collagen by approximately $60 \%$ compared with controls (Figure 8F).
Given these results, it is possible that the reduction of $\alpha$-SMA-positive stromal cells observed after anti-HU177 treatment leads to a reduction in an important source of protumorigenic cytokines that facilitate tumor growth and angiogenesis. To this end, we examined whether CM from $\alpha$-SMA-expressing fibroblasts might contain soluble factors that enhance SKOV-3 cell growth. Fibroblast CM enhanced proliferation and $\mathrm{Ki}-67$ antigen expression in SKOV-3 cells (Figure 8, G and $\mathrm{H}$ ). These results are consistent with the ability of soluble factors released into the conditioned medium of these $\alpha_{10} \beta_{1}$-expressing fibroblasts to 
enhance SKOV-3 tumor cell proliferation in vitro. To characterize potential protumorigenic factors expressed by these $\alpha$-SMA-positive fibroblasts, concentrated serum free $\mathrm{CM}$ was screened using a multianalyte cytokine array for expression of 12 different cytokines. Among the cytokines that were expressed at the highest levels was IL-6 (Supplemental Table S1). Interestingly, IL-6 enhances growth of ovarian carcinoma cells ${ }^{49,50}$; thus, we examined whether this protumorigenic cytokine played a functional role in mediating the ability of $\alpha$-SMA-expressing fibroblast CM to stimulate proliferation of SKOV-3 tumor cells. Fibroblast CM significantly enhanced SKOV-3 tumor cell proliferation, and a function-blocking antibody directed to IL-6 inhibited this response (Figure 8I). These data are consistent with a role for IL-6 expression from fibroblasts in promoting SKOV-3 tumor cell growth. Taken together, these findings suggest the possibility that $\alpha$-SMAexpressing fibroblasts may serve as an important source of protumorigenic factors that facilitate SKOV-3 tumor growth and that selectively reducing accumulation of $\alpha$-SMAexpressing stromal cells by inhibiting the interactions of these cells with the HU177 collagen epitope may contribute to the potent antitumor activity observed in vivo.

\section{Discussion}

The array of mechanisms by which stromal cells, such as endothelial cells and activated $\alpha$-SMA-expressing fibroblasts, govern the malignant phenotype are diverse and include providing proteolytic enzymes that alter the biomechanical properties of ECM; the release of protumorigenic factors that act on both tumor and other cell types to alter their growth, survival, and migratory behavior; and the release of molecules that influence the host immune response. ${ }^{1-6,51,52}$ Thus, selectively blocking the accumulation of protumorigenic stromal cells in malignant lesions likely represents an important therapeutic strategy. Although targeting stromal cells may provide a complementary strategy for tumor therapy, it remains challenging to selectively target them without disrupting their activity in normal tissues. The ECM represents an active control point for multiple mechanisms critical for regulating stromal cell behaviors, ranging from migration and proliferation to gene expression. ${ }^{14}$ Therefore, inhibiting stromal cell-ECM interaction that selectively limits the accumulation of protumorigenic stromal cells in malignant lesions might represent a useful strategy to control tumor progression.

We found that the HU177 collagen epitope is abundantly generated within ovarian carcinomas compared with benign ovarian lesions. Importantly, previous studies have indicated that proteolytic enzymes, such as matrix metalloproteinase, can contribute to generation of the HU177 epitope in vivo. ${ }^{16}$ We provide evidence that this cryptic collagen epitope played a role in SKOV-3 tumor growth, and these findings are consistent with a clinical trial that assessed tolerability and toxicity of mAb D93/TRC093. ${ }^{20}$ Results of this study suggested no dose-limiting toxic effects and evidence of antitumor activity because a patient with an ovarian cancer had a reduction in metastatic liver lesions. ${ }^{20}$ Although all cancers eventually progressed, $26 \%$ of patients had disease stabilization, and a patient with hemangiopericytoma, a tumor known to be highly infiltrated with stromal cells, had stable disease for nearly a year. ${ }^{20}$

Consistent with previous findings ${ }^{15,18}$ the anti-HU177 antibody inhibited tumor-associated angiogenesis. These data are in agreement with previous studies that indicate that targeting the HU177 epitope could selectively inhibit endothelial cell adhesion and migration on denatured collagen, inhibit proliferation, up-regulate expression of P27KIP1, and inhibit angiogenesis in vivo. ${ }^{15}$ Surprisingly, our new studies now indicate that targeting the HU177 epitope can also reduce the accumulation of $\alpha$-SMA-expressing stromal cells within SKOV-3 tumors. Targeting the HU177 epitope inhibited SKOV-3 and $\alpha$-SMA-expressing fibroblast adhesion and migration on denatured but not intact collagen, thereby specifically limiting the effect of this therapeutic agent to those tissues that express the HU177 epitope. FGF2 -induced fibroblast migration on denatured collagen was dependent in part on MAP/Erk signaling because inhibition of MAP/Erk signaling blocked this migratory response.

Cell migration is governed by a complex and integrated set of signaling events that are coordinated in part by the unique composition and integrity of the local ECM. However, the mechanisms by which cells sense the structural changes in the integrity of a given ECM environment during tumor growth to facilitate cellular motility induced by growth factors are not completely understood. In fact, inappropriate and/or enhanced migration may contribute to tumor cell invasion and metastasis as well as the accumulation of CAF-like stromal cells that contribute to tumor progression. Integrin-mediated interactions with ECM proteins are known to initiate assembly of multiple-protein complexes that coordinately regulate downstream signaling cascades, including Shc/Grab2/Ras and Fak/Src/Rap1 pathways that can activate MAPK/Erk signaling. ${ }^{41}$ Our novel finding suggests that FGF-2 can enhance the phosphorylation of Erk in $\alpha_{10} \beta_{1}$-expressing fibroblasts and a function-blocking antibody directed to the HU177 cryptic collagen epitope inhibited Erk phosphorylation. Given that MAPK/Erk signaling plays a role in the ability of $\alpha_{10} \beta_{1}$-expressing fibroblasts to migrate on denatured collagen and the fact that denatured collagen selectively generates within the tumor microenvironment, ${ }^{12,13,15,18}$ it would be interesting to speculate that the selective generation of the HU177 epitope within the ovarian tumor microenvironment may help facilitate enhanced activation of Erk, which may promote stromal cell migration and subsequent accumulation in tumors. Although multiple protein kinases contribute to the phosphorylation of Erk, the precise molecular mechanism by which cellular interactions with the HU177 epitope regulates FGF-2-induced activation of Erk is not known. Studies are currently under way to 
define which kinases and/or phosphatases might contribute to the FGF-2-mediated regulation of Erk after interactions with the HU177 collagen epitope.

Given the reduction in $\alpha$-SMA-expressing cells in tumors treated with anti-HU177 antagonists, selectively inhibiting migration of this population of stromal cells may limit a major cellular source of protumorigenic factors that play multiple roles in facilitating tumor cell survival and proliferation in vivo. In this regard, fibroblasts are known to express many protumorigenic factors, including IL-6, which has been previously found to enhance proliferation of ovarian carcinoma cells. ${ }^{38,49,50}$ Consistent with these findings, our studies suggest that blocking IL-6 inhibited fibroblast CMinduced SKOV-3 cell growth. Given these findings and the high levels of IL-6 expressed by fibroblasts, our data are consistent with a mechanism by which targeting the HU177 epitope selectively limits accumulation of $\alpha$-SMA fibroblasts, thereby reducing an important source of protumorigenic factors that enhance angiogenesis and tumor growth.

We provide new evidence that the little understood integrin $\alpha_{10} \beta_{1}$ functions as a receptor for the HU177 collagen epitope in fibroblasts. Given the variations within the HU177 PGxPG consensus site and the possibility of unique geometrical configurations and distinct flanking amino acid sequences found in vivo, it is possible that additional receptors may also recognize the HU177 epitope. Interestingly, little is known about the functions of $\alpha_{10} \beta_{1}$ outside chondrocyte and growth plate development. ${ }^{45-48}$ However, $\alpha_{10}$ mRNA has been detected in murine heart, muscle tissues, and endothelial cells. ${ }^{45-48}$ Studies suggest that FGF-2 stimulation of mesenchymal stem cells leads to up-regulation of $\alpha_{10} \cdot{ }^{53}$ Moreover, mesenchymal stem cells have also been implicated as potential sources of $\alpha$-SMAexpressing CAF-like cells in tumors. ${ }^{54}$ In addition, studies now suggest enhanced expression of $\alpha_{10} \beta_{1}$ in melanoma cell lines compared with primary melanocytes and inhibiting $\alpha_{10} \beta_{1}$ in these cells resulted in a reduced migration. ${ }^{55}$

Given the ability of $\alpha_{10} \beta_{1}$ to bind the HU177 epitope, our data agree with a novel mechanism by which generation of the HU177 epitope provides a previously unrecognized ligand for $\alpha_{10} \beta_{1}$-expressing stromal cells that facilitates FGF2 -induced activation of Erk and subsequently the accumulation of $\alpha$-SMA-positive stromal cells in ovarian tumors. In turn, the selective reduction in accumulation of this cell population by anti-HU177 antibody, in conjunction with its previously described antiangiogenic effects, likely contributes to its potent antitumor activity. Taken together, our findings provide new cellular and molecular insight into the roles of the HU177 cryptic epitope in ovarian tumor growth and provide new mechanistic understanding of the therapeutic effect observed in humans treated with mAb D93/TRC093. ${ }^{20}$

\section{Supplemental Data}

Supplemental material for this article can be found at http://dx.doi.org/10.1016/j.ajpath.2016.01.015.

\section{References}

1. Mursap N, Diamandis EP: Revisiting the complexity of the ovarian cancer microenvironment-clinical implications for treatment strategies. Mol Cancer Res 2012, 10:1254-1264

2. Schauer IG, Sood AK, Mok A, Liu J: Cancer associated fibroblasts and their putative role in potentiating the initiation and development of epithelial ovarian cancer. Neoplasia 2011, 13:393-405

3. Hanahan D, Coussens LM: Accessories to the crime: functions of cells recruited to the tumor microenvironment. Cancer Cell 2012, 21 : 309-421

4. Qian BZ, Pollard JW: Macrophage diversity enhances tumor progression and metastasis. Cell 2010, 141:39-51

5. Bansai R, Tomar T, Ostman A, Poelstra K, Prakash J: Selective targeting of interferon $\gamma$ to stromal fibroblasts and pericytes as a novel therapeutic approach to inhibit angiogenesis and tumor growth. Mol Cancer Ther 2012, 11:2419-2428

6. Mitra AK, Zillhardt M, Hua Y, Tiwari P, Murmann AE, Peter ME Lengyel E: MicroRNAs reprogram normal fibroblasts into cancerassociated fibroblast in ovarian cancer. Cancer Discov 2012, 2: $1100-1108$

7. Yao Q, Qu X, Yang Q, Mingqian W, Kong B: CLIC4 mediates TGF- $\beta 1$-induced fibroblast-to-myofibroblast trans differentiation in ovarian cancer. Oncol Rep 2009, 22:541-548

8. Crawford Y, Kasman I, Yu L, Zhong C, Wu X, Modrusan Z, Kaminker J, Ferrara N: PDGF-C mediates the angiogenic and tumorigenic properties of fibroblasts associated with tumors refractory to anti-VEGF treatment. Cancer Cell 2009, 15:21-34

9. Ricciardelli C, Rodgers RJ: Extracellular matrix of ovarian tumors. Semin Reprod Med 2006, 24:270-282

10. Capo-Chichi CD, Smith ER, Yang DH, Roland IH, Vanderveer L, Hamiliton TC, Godwin AK, Xu XX: Dynamic alterations of the extracellular matrix environment of ovarian surface epithelial cells in premalignant transformation, tumorigenicity, and metastasis. Cancer 2002, 95:1802-1815

11. Akalu A, Roth JM, Caunt M, Policarpio D, Liebes L, Brooks PC: Inhibition of angiogenesis and tumor metastasis by targeting a matrix immobilized cryptic extracellular matrix epitope in laminin. Cancer Res 2007, 67:4353-4363

12. Hangai M, Kitaya N, Xu J, Chan CK, Kim JJ, Werb Z, Ryan SJ, Brooks PC: Matrix metalloproteinase-9-dependent exposure of a cryptic migratory control site in collagen is required before retinal angiogenesis. Am J Pathol 2002, 161:1429-1437

13. Xu J, Rodriguez D, Petitclerc E, Kim JJ, Hangai M, Yuen SM, Davis GE, Brooks PC: Proteolytic exposure of a cryptic site within collagen type-IV is required for angiogenesis and tumor growth in vivo. J Cell Biol 2001, 154:1069-1079

14. Cretu A, Brooks PC: Impact of the non-cellular microenvironment on metastasis: potential therapeutic and imaging opportunities. J Cell Physiol 2007, 213:391-402

15. Cretu A, Roth JM, Caunt M, Policarpio D, Formenti S, Gange P, Liebes L, Brooks PC: Disruption of endothelial cell interactions with the novel HU177 cryptic collagen epitope inhibits angiogenesis. Clin Cancer Res 2007, 13:3068-3078

16. Gagne PJ, Tihonov N, Li X, Glaser J, Qiao J, Silberstein M, Yee H, Gagne E, Brooks PC: Temporal exposure of cryptic collagen epitopes within ischemic muscle during hindlimb reperfusion. Am J Pathol 2005, 167:1349-1359

17. Ames JJ, Vary CPH, Brooks PC: Signaling pathways and molecular mediators in metastasis. Biomechanical ECM Switches and Tumor Metastasis. Springer Press 2012, 3:71-89

18. Pernasetti F, Nickel J, Clark D, Baeurle PA, Van Epps D, Freimark B Novel anti-denatured collagen humanized antibody D93 inhibits angiogenesis and tumor growth: an extracellular matrix-based therapeutic approach. Int J Oncol 2006, 29:1371-1379

19. Freimark B, Clark D, Pernasetti F, Kickel J, Myszka D, Baeuerle PA, van Epps D: Targeting of humanized antibody D93 to sites of 
angiogenesis and tumor growth by binding to multiple epitopes on denatured collagens. Mol Immunol 2007, 44:3741-3750

20. Robert F, Gordon MS, Rosen LS, Mendelson DS, Mulay M, Adams BJ, Alvare D, Theuer CP, Leigh BR: Final results from a phase I study of TRC093 (humanized anti-cleaved collagen antibody) in patients with solid cancer. Annual meeting proceedings, 2010, ASCO. Abstract No 3038 .

21. Romero I, Bast RC: Minireview: human ovarian cancer: biology, current management, and paths to personalized therapy. Endocrinol 2012, 154:1593-1602

22. Vaughan S, Coward JI, Bast RC, Berchuck A, Berek JS, Brenton JD, Coukos G, Crum CC, Drapkin R, Etemadmoghadam D, Friedlander M, Gabra H, Kaye SB, Lord CJ, Lengyel E, Levine DA, McNeish IA, Menon U, Mills GB, Nephew KP, Oza AM, Sood AK, Stronach EA, Walczak H, Bowtell DD, Balkwill FR: Rethinking ovarian cancer: recommendations for improving outcomes. Nat Rev Cancer 2011, 11:719-725

23. Kuman RJ, Shih M: The origin and pathogenesis of epithelial ovarian cancer: a proposed unifying theory. Am J Surg Pathol 2010, 34: 433-443

24. Kim J, Coffey DM, Creighton CJ, Yu Z, Hawkins SM: High-grade serous ovarian cancer arises from fallopian tube in a mouse model. Proc Natl Acad Sci U S A 2012, 109:3921-3926

25. Ozols RF, Bookman MA, Connolly DC, Daly MB, Godwin AK, Schilder RJ, Xu X, Hamilton TC: Focus on epithelial ovarian cancer. Cancer Cell 2004, 5:19-24

26. Granot D, Addadi Y, Kalchenko V, Harmelin A, Kunz-Schugart LA, Neeman M: In vivo imaging of systemic recruitment of fibroblasts to the angiogenic rim of ovarian carcinoma tumors. Cancer Res 2007, 67:9180-9190

27. Cai J, Tang H, Xu L, Wang X, Yang C, Ruan S, Guo J, Hu S, Wang Z: Fibroblasts in omentum activated by tumor cells promote ovarian cancer growth, adhesion and invasiveness. Carcinogenesis 2013, 33:20-29

28. Ko SY, Barengo N, Ladanyi A, Lee JS, Marini F, Lengyel E, Naora H: HoxA9 promotes ovarian cancer growth by stimulating cancer-associated fibroblasts. J Clin Invest 2012, 122:3603-3617

29. Roth JM, Zelmanovich A, Policarpio D, Ng B, MacDonald S, Formenti S, Liebes L, Brooks PC: Recombinant $\alpha 2$ (IV) NC1 domain inhibits tumor cell-extracellular matrix interactions, induces cellular senescence, and inhibits tumor growth in vivo. Am J Pathol 2005, 166:901-911

30. Brooks PC, Montgomery AM, Rosenfeld M, Reisfeld RA, Hu T, Klier G, Cheresh DA: Integrin $\alpha v \beta 3$ antagonists promote tumor regression by inducing apoptosis of angiogenic blood vessels. Cell 1994, 79:1157-1164

31. Zhu GG, Melkko J, Risteli J, Kauppila A, Risteli L: Differential processing of collagen type-I and type III procollagens in the tumor cysts and peritoneal ascites fluid of patients with benign and malignant ovarian tumors. Clin Chim Acta 1994, 229:87-97

32. Santala M, Risteli J, Risteli L, Pulstola U, Kacinski BM, Stanley ER, Kauppila A: Synthesis and breakdown of fibrillar collagens: concomitant phenomena in ovarian cancer. Br J Cancer 1998, 77: $1825-1831$

33. Kawamura K, Komohara Y, Takaishi K, Katabuchi H, Takeya M: Detection of M2 macrophages and colony stimulating factor 1 expression in serous and mucinous ovarian epithelial tumors. Pathol Int 2009, 59:300-305

34. Cubillos-Ruiz JR, Rutkowski M, Conejo-Garcia JR: Blocking ovarian cancer progression by targeting tumor microenvironmental leukocytes. Cell Cycle 2010, 9:260-268

35. Petitclerc E, Stromblad S, von Schalscha TL, Mitjans F, Piulats J, Montgomery AM, Cheresh DA, Brooks PC: Integrin $\alpha_{\mathrm{v}} \beta_{3}$ promotes M21 melanoma growth in human skin by regulating tumor cell survival. Cancer Res 1999, 59:2724-2730

36. Anderberg C, Pietras K: On the origin of cancer-associated fibroblasts. Cell Cycle 2009, 8:1461-1465
37. Erez N, Truitt M, Olsen P, Hanahan D: Cancer-associated fibroblasts are activated in incipient neoplasia to orchestrate tumor-promoting inflammation in an NFkb-dependent manner. Cancer Cell 2010, 17: $135-147$

38. Erez N, Glanz S, Raz Y, Avivi C, Barshack I: Cancer associated fibroblasts express pro-inflammatory factors in human breast and ovarian tumors. Biochem Biophys Res Commun 2013, 437:397-402

39. Cunningham DL, Sweet SMM, Cooper HJ, Heath JK: Differential phosphoproteomics of fibroblast growth factor signaling: identification of Src family kinase-mediated phosphorylation events. J Proteome Res 2010, 9:2317-2328

40. Kanda S, Miyata Y, Kanetake H, Smithgall TE: Fibroblast growth factor-2 induces the activation of Src through Fes, which regulates focal adhesion disassembly. Exp Cell Res 2006, 312:3015-3022

41. Barberis L, Wary KK, Fiucci G, Liu F, Hirsch E, Brancaccio M, Altruda F, Tarone G, Giancotti FG: Distinct roles of the adaptor protein Shc and focal adhesion kinase in integrin signaling to Erk. J Biol Chem 2000, 275:36532-36540

42. Cho AY, Klemke RL: Extracellular-regulated kinase activation and CAS/Crk coupling regulate cell migration and suppress apoptosis during invasion of the extracellular matrix. J Cell Biol 2000, 149:223-236

43. Kottakis F, Polytarchou C, Foltopoulou P, Sanidas I, Kampranis SC, Tsichlis PN: FGF-2 regulates cell proliferation, migration and angiogenesis through an NDY1/KDM2B-miR-101-EZH2 pathway. Mol Cell 2011, 43:285-298

44. Boilly B, Vercoutter-Edouart AS, Hondermarck H, Nurcombe V, Bourhis XL: FGF signals for cell proliferation and migration through different pathways. Cytokine Growth Factor Rev 2000, 11:295-302

45. Lehnert K, Ni J, Leung E, Gough S, Morris CM, Liu D, Wang SX, Langley R, Krissansen GW: The integrin $\alpha_{10}$ subunit: expression pattern, partial gene structure, and chromosomal localization. Cytogent Cell Genet 1998, 87:238-244

46. Bengtsson T, Camper L, Schneller M, Lundgren-Akerlund E: Characterization of the mouse integrin subunit $\alpha_{10}$ gene and comparison with its human homologue genomic structure, chromosomal localization and identification of splice variants. Matrix Biol 2001, 20:565-576

47. Bengtsson T, Aszodi A, Nicolae C, Hunziker EB, Lundgren-Akerlund E, Fassler R: Loss of $\alpha_{10} \beta_{1}$ integrin expression leads to moderate dysfunction of growth plate chondrocytes. J Cell Sci 2004, 118:929-936

48. Camper L, Holmvall K, Wangnerd C, Asodi A, LundgrenAkerlund E: Distribution of the collagen-binding integrin $\alpha_{10} \beta_{1}$ during mouse development. Cell Tissue Res 2001, 306:107-116

49. Wang Y, Li L, Jin X, Sun W, Zhang X, Xu RC: Interleukin-6 signaling regulates anchorage-independent growth, proliferation, adhesion and invasion in human ovarian cancer cells. Cytokine 2012, 59:228-236

50. Wang Y, Xu RC, Zhang XL, Niu XL, Qu Y, Li LZ, Meng XY: Interleukine-8 secretion by ovarian cancer cells increases anchorageindependent growth, proliferation, angiogenic potential, adhesion and invasion. Cytokine 2012, 59:145-155

51. Santos AM, Jung J, Aziz N, Kissil JL, Pure E: Targeting fibroblast activation protein inhibits tumor stromagenesis and growth in mice. J Clin Invest 2009, 119:3613-3625

52. Kraman M, Bambrough PJ, Arnold JN, Roberts EW, Magiera L, Jones JO, Gopinathan A, Tuveson DA, Fearon DT: Suppression of anti-tumor immunity by stromal cells expressing fibroblast activation protein- $\alpha$. Science 2001, 250:827-830

53. Varas L, Ohlsson LB, Honeth G, Olsson A, Bengtsson T, Wiberg C, Bockermann R, Järnum S, Richter J, Pennington D, Johnstone B, Lundgren-Akerlund $\mathrm{E}$, Kjellman $\mathrm{C}: \alpha_{10}$ integrin expression is upregulated on fibroblast growth factor-2-treated mesenchymal stem cells with improved chondrogenic differential potential. Stem Cell Develop 2007, 16:965-978

54. Mishra PJ, Mishra PJ, Glod JW, Banerijee D: Mesenchymal stem cells: flip side of the coin. Cancer Res 2009, 69:1255-1258

55. Wenke AK, Kjellman C, Lundgren-Akerlund E, Uhlmann C, Haass NK, Herlyn M, Bosserhoff AK: Expression of integrin $\alpha_{10}$ is induced in malignant melanoma. Cell Oncol 2007, 29:373-386 